\title{
T4c Stage Finding
}

National Cancer Institute

\section{Source}

National Cancer Institute. T4c Stage Finding. NCI Thesaurus. Code C48735.

A general term that refers to a TNM finding of a primary tumor with direct invasion of adjacent structures. The definition of T4C TNM finding depends on the specific type of cancer that it refers to; for example, for breast cancer it refers to a primary tumor that extends to the chest wall, not including the pectoralis muscle, and with edema (including peau d'orange) or ulceration of the skin of the breast or satellite skin nodules confined to the same breast; for ocular adnexal lymphoma it refers to a primary tumor that Involves the maxillofacial, ethmoidal, and/or frontal sinuses; for carcinoma of the conjunctiva it refers to a primary tumor that invades adjacent paranasal sinuses. 